\title{
Comparison of the Effect of the Fascial Distortion Model, Foam Rolling and Self-Stretching on the Ankle Dorsiflexion Range of Motion
}

\author{
Seol Park', Ji-Young Kim² \\ 'Department of Physical Therapy, College of Health Science, Catholic University of Daegu, Daegu, Korea; ${ }^{2}$ Department of Physical Therapy, Masan \\ University, Masan, Korea
}

Purpose: This study compared the effects of the fascial distortion model (FDM), foam rolling (FR), and self-stretching (SS) on the ankle dorsiflexion range of motion (ROM).

Methods: Thirty subjects who had no more than $30^{\circ}$ of ankle dorsiflexion ROM at the weight-bearing lunge test were recruited in this study. They were divided into three groups: (FDM, FR, and SS), and underwent each intervention for five minutes. Before and after the intervention, the ankle dorsiflexion ROM in the supine (the open-) and standing (the closed-kinetic chain) of the subjects were tested. The changes in the ROM between pre- and post-intervention and among the groups were analyzed.

Results: All groups showed increased ankle dorsiflexion ROM after the intervention in both positions. In the position of the open kinetic chain, the changes in the ROM between pre- and post-intervention had significant differences among the groups, and the FDM was higher than the FR and SS. In the position of the closed kinetic chain, the ROM after the interventions and the changes in the ROM had significant differences among the groups, and FDM was higher than the FR (ROM after the intervention, the change in ROM) and SS (the change in ROM).

Conclusion: These findings showed that FDM had more efficiency than the FR and SS as FDM had a stronger effect on increasing ankle dorsiflexion in a short, limited time. Clinicians who have limited time to treat their patients, particularly trying to increase ankle dorsiflexion ROM, should consider the application of FDM.

Keywords: Fascia, Ankle, Range of motion, Fascial Distortion Model

\section{서 론}

최근 십 수년간 근막(fascia)에 대한 연구가 활발히 진행되면서 근막 은 단순히 근육을 싸고 있는 막이라는 기존의 통념과는 달리 인체 구 조를 지지하고 전신에 3차원적인 연결을 연속적으로 형성하는 연부 조직이라는 개념이 받아들여 지고 있으며, ${ }^{1}$ 이러한 근막의 특성을 이 용해 통증 및 기능부전을 치료하는 접근법에 대한 관심 또한 높아지 고 있다. 이러한 근막 치료 접근법에는 근막변형모델(Fascial distortion model, FDM), 근막 도수치료(Fascial manipulation), ${ }^{2}$ 그라스톤(Graston) 과 같은 도구를 이용한 연부조직가동술(Instrument-assisted soft tissue mobilization), ${ }^{3}$ 폼롤러(Foam roller) 등을 이용한 자가 근막 이완(Selfmyofascial release, $\mathrm{SMR})^{3}$ 등이 있다.

FDM은 1991년 미국 의사인 Stephen Typaldos에 의해 개발된 근막
치료 접근법으로, ${ }^{4}$ 2006년 유럽 FDM 학회(European Fascial Distortion Model Association)에서 교육을 시작한 이후로 정골의사(osteopath), 물리치료사, 의사 등을 대상으로 한국을 포함해 미국, 독일, 일본, 아 프리카 등 많은 나라에서 교육이 활발히 이루어지고 있다.

근막의 변형은 근육뼈대계를 손상시키며, 이러한 근막의 변형을 물리적인 외력으로 반전시킴으로써 원래의 상태로 회복할 수 있다는 가설을 바탕으로 시행하는 것이 FDM이다. 목 통증, 굳은어깨(frozen shoulder), ${ }^{6}$ 안쪽 정강이 스트레스 증후군(medial tibial stress syndrome), 절음발이(limp), ${ }^{8}$ 허리통증, ${ }^{9}$ 척추옆굽음증 ${ }^{10}$ 등 다양한 질환 이나 병적 증상에서 통증 감소와 기능 향상에 효과적이지만, 무엇보 다 빠른 시간 안에 통증이나 기능 부전을 개선시킬 수 있다는 것이 $\mathrm{FDM}$ 의 가장 큰 장점이다.,6,9 하지만 비교적 최신의 치료 모델이라는 점, 근막에 대한 연구가 최근 들어 활발히 진행되고 있다는 점 등의 
이유로 FDM의 효과를 검증한 대부분의 연구들이 사례 연구로 진행 되었거나 피험자 수가 적었으며, 따라서 $\mathrm{FDM}$ 의 효과를 검증한 양질 의 연구가 부족하다. ${ }^{11}$

SMR 기법은 도구를 사용하여 통증 부위에 압력을 가함으로써 통 증을 경감시키고 근막의 가동성을 향상시키는 근막 치료 접근법으 로, 도구 사용법이 쉽고 간편해 임상에서 운동선수, 환자 및 일반인 들에게 널리 사용되고 있다. ${ }^{12,13}$ 특히, 폼롤러를 이용한 자가근막이완 기법, 즉, 폼롤링(foam rolling)은 단시간 짧은 횟수의 적용 만으로도 효과가 입증되었으며, ${ }^{14}$ 통증 감소, ${ }^{15}$ 관절 가동범위(range of motion, $\mathrm{ROM})$ 증가 ${ }^{16}$ 운동 수행능력 향상 15,17 등에 효과적이다.

장딴지근을 비롯한 종아리세갈래근(triceps surae)의 단축 등으로 인해 발생하는 발목관절 발등굽힘(dorsiflexion, DF)의 ROM 제한은 정상 보행에 영향을 미치며 하지 관절의 부상 위험을 증가시킨다. ${ }^{18}$ 특 히 닫힌 사슬에서 측정한 $\mathrm{DF}$ 의 $\mathrm{ROM}$ 이 30 도 이하일 경우에는 부상 을 예측할 수 있으며, ${ }^{19}$ 꿈치들린휜발(ankle equinus)의 기준으로 활용 된다. ${ }^{20}$ 본 연구에서는 닫힌 사슬에서 $\mathrm{DF}$ 의 $\mathrm{ROM}$ 이 30 도 이하인 성인 을 대상으로 FDM, 폼롤링, 그리고 일반적으로 수건을 활용하여 수행 하는 종아리세갈래근의 자가 신장(self-stretching)을 대조군으로 각 각 적용하였을 경우 $\mathrm{DF}$ 의 $\mathrm{ROM}$ 에 미치는 효과를 비교하고자 하였다. 이를 통해 FDM의 적용이 빠른 시간 내에 ROM 개선 효과를 보여줄 수 있는지를 증명하고자 하였다.

\section{연구 방법}

\section{1. 연구대상}

본 실험에 참여한 피험자들은 총 30 명으로, 체중 부하 런지 검사 (weight-bearing lunge test, WBLT)에서 $30^{\circ}$ 이하인 자로 선별하였다 (Table 1). WBLT는 신뢰도가 검증된 검사 방법으로, ${ }^{21,22}$ 바로 선 자세 에서 비실험측 다리를 앞으로 내밀 때 실험측 무릎이 펴진 상태에서 발뒤꿈치가 땅에서 떨어지기 직전의 $\mathrm{DF}$ 각도를 측정하였다. 측정하 는 발은 양쪽 발목 중 DF ROM의 제한이 더 심한 쪽을 선택하도록 하

Table 1. General characteristics of subjects

$($ mean $\pm S D)$

\begin{tabular}{lcccc}
\hline & FDM & FR & SS & $p$ \\
\hline N (M:F) & $10(5: 5)$ & $10(5: 5)$ & $10(5: 5)$ & \\
Age (yr) & $22.6 \pm 1.96$ & $24.1 \pm 3.73$ & $22.7 \pm 2.54$ & 0.44 \\
Height $(\mathrm{cm})$ & $169.8 \pm 10.10$ & $168.6 \pm 7.24$ & $168.7 \pm 12.96$ & 0.96 \\
Weight $(\mathrm{kg})$ & $76.4 \pm 16.75$ & $58.7 \pm 23.65$ & $61.1 \pm 12.64$ & 0.10 \\
WBLT $\left.^{\circ}\right)^{\ddagger}$ & $18.8 \pm 7.81$ & $16.2 \pm 6.65$ & $17.6 \pm 4.01$ & 0.67 \\
Dominant (R:L) & $9: 01$ & $10: 00$ & $9: 01$ & \\
\hline
\end{tabular}

${ }^{\ddagger}$ Inclusion criteria $\left(\leq 30^{\circ}\right)$

SD: Standard deviation, FDM: Fascial distortion model group, FR: Foam rolling group, SS: Self-stretching group, WBLT: Weight-bearing lunge test.
였으며, 양쪽이 같을 경우 우세측 다리로 선정하고자 하였다. 우세측 발은 공을 찰 때 주로 쓰는 발, 한 발로 뛸 때 디딤발, 또는 계단 오를 때 먼저 내딛는 발 등 세 가지 질문에 두 가지 이상 일치하는 발로 정 하였다. 그 결과 본 실험에 참여한 모든 피험자들의 우세측 발목이 $\mathrm{ROM}$ 을 측정하는 데 동원되었다. 실험 전 6개월 이내에 하지 관절의 정형외과적, 신경외과적 수술이나 부상의 경험이 있는 자, 균형 능력 에 문제가 있는 자, 실험 당시 종아리세갈래근에 대한 치료를 받고 있 는 자는 제외하였다. 실험 전 피험자들에게 본 연구의 목적 및 위험성 에 대해 사전에 충분히 설명하였으며, 모든 피험자들은 본 실험에 대 해 동의하였다.

\section{2. 실험방법}

\section{1) 그룹 분류}

실험 전 피험자들의 나이, 키, 몸무게, 우세측 발을 기록하였다. 이후 피험자들을 $\mathrm{FDM}$ 그룹(FDM), 폼롤링 그룹(FR), 그리고 대조군으로 수건을 이용한 자가 신장 그룹(SS) 등 세 그룹으로 할당하였다. Gaj$\operatorname{dosik}$ 등 ${ }^{23}$ 에 따르면 치료 목적의 스트레칭을 적용할 경우 남녀 간에 다르게 반응한다고 하였으므로 성별 분배의 치우침을 배제하고 내 적 타당도를 확보하기 위해 짝짓기 설계(matched subject design)을 하 여 각 그룹 내에 남녀의 비율이 5:5가 되도록 하였다. 이를 위해 남성 과 여성을 분류하였으며, 무작위 할당을 위해 세 그룹의 이름이 적힌 종이를 한장씩 뽑도록 하였다.

\section{2) $\mathrm{ROM}$ 측정}

각 중재를 적용하기 전과 후의 $\mathrm{DF} \mathrm{ROM}$ 차이를 비교하기 위해 열린 사슬과 닫힌 사슬 두 위치에서 $\mathrm{DF}$ 의 $\mathrm{ROM}$ 을 측정하였으며, 이때 각 도계(Jamar, USA)를 사용하였다. 열린 사슬에서의 DF ROM은 바로 누운 자세에서 발목의 능동 $\mathrm{DF}$ 시 $\mathrm{ROM}$ 을 측정하였으며, 각도계의 고정팔은 종아리뼈머리(fibular head)와 가쪽복사뼈(lateral malleolus) 를 이은 가상의 선과 일치시켰으며, 움직팔은 다섯 번째 발허리뼈(5th metatarsal)와 일치시켰다. 발목관절이 $90^{\circ}$ 를 이루었을 때를 DF ROM $0^{\circ}$ 로 설정하여 DF ROM을 측정하였다. 닫힌 사슬에서의 DF ROM은 WBLT에서의 각도를 측정하였으며, 이때의 고정팔과 움직팔은 열린 사슬과 반대로 적용하였다. ROM은 각 자세에서 두 번 측정 후 평균 값을 사용하였다.

\section{3) 중재 방법 \\ (1) 근막변형모델(FDM)}

$\mathrm{FDM}$ 은 빠른 시간 내에 통증과 기능을 개선할 수 있는 치료 방법으 로, 근막의 특정한 변화에 대한 결과로 근골격계가 손상된다는 가정 하에 변형된 근막을 반전시켜 정상적인 수준으로 되돌림으로써 회 
복시킨다는 가설을 기반으로 근막 변형의 유형을 Trigger point (TB), Cylinder distortion (CyD), Continuum distortion, Herniated trigger point, Folding distortion, Tectonic fixation 등 6가지로 구분한다. 그 중 본 실험에서는 가장 흔한 형태의 유형인 $\mathrm{TB}$ 를 적용하였으며, $\mathrm{TB}$ 적용 후 CyD로 FDM 치료를 마무리하였다(Figure 1).

$\mathrm{TB}$ 는 가장 흔한 형태의 근막 변형 유형으로, 밴드형의 근막(banded fascia)이 뒤틀리거나 분리되는 경우, 또는 찢어지거나 만성화되어 석회화가 이루어진 상태를 의미한다.,24이 경우 변형된 근막을 지나 는 선을 따라 통증을 호소하며, 해당 관절, 또는 인접 관절에서 기능 장애를 유발한다. 이 변형은 뒤틀린 상태의 밴드형 근막을 물리적인 압력으로 펴 주는 도수치료를 통해 정상 상태의 근막으로 회복시키 게 된다.,24 $\mathrm{TB}$ 의 기본적인 적용 방법은 엄지 등을 이용하여 치료하고 자 하는 부위의 몸쪽 뼈 돌출부에서 먼쪽 뼈 돌출부까지 선을 따라 강한 압력을 주는 것이다. ${ }^{24} \mathrm{FDM}$ 에서는 환자가 통증을 호소하는 부 위에 적용하는 것을 원칙으로 하며, 환자가 가리키는 신체적 언어 (body language)에 기초하여 치료 방향을 설정하지만, 본 실험에서는 $\mathrm{EFDMA}$ 에서 진행하는 $\mathrm{FDM}$ 교육 내용 중 종아리세갈래근 부위에 적용할 수 있는 TB인 Posterior lateral TB, Posterior medial TB, Posterior TB, Lateral Achilles tendon TB를 적용하였다. Posterior lateral TB는 종 아리뼈머리에서 시작하여 가쪽 복사뼈의 뒤쪽을 지나 새끼발가락까 지 이어지는 선을 따라 엄지손가락으로 강한 압력을 제공하는 방법 이며(Figure 1A, 엄지손가락 위치에서 시작하는 선), posterior medial $\mathrm{TB}$ 는 몸쪽 정강뼈(tibia)의 뼈 돌출부에서 시작하여 안쪽 복사뼈(medial malleolus) 뒤쪽을 지나 엄지발가락 끝까지 이어지는 선을 따라 압력을 제공한다. ${ }^{24}$ Posterior TB는 앞서 기술한 두 $\mathrm{TB}$ 사이를 지나가 며, 오금 부위에서 시작하여 장딴지근(gastrocnemius)의 두 머리 사이 로 깊게 주행하고, Achilles 힘줄을 지나 발꿈치뼈(calcaneous) 끝에서 정지한다(Figure $1 \mathrm{~B}$, 엄지손가락 위치에서 시작하는 선). ${ }^{24}$ Lateral Achilles tendon $\mathrm{TB}$ 는 장딴지근의 근복 아래에서 시작하여 Achilles 힘
줄의 가쪽을 지나 발꿈치뼈의 가쪽에서 정지하는 기법이다. ${ }^{24}$ Figure $1 \mathrm{~A}$ 와 $\mathrm{B}$ 는 앞서 설명한 네 가지 종류의 $\mathrm{TB}$ 를 빨간색 선으로 표시한 것 이며, 치료사는 선의 몸쪽 끝부분에서 시작하여 빨간 선을 따라 먼 쪽 끝부분까지 엄지손가락으로 강한 압력을 주면서 밀도록 하였다. 각 $\mathrm{TB}$ 적용 후 30 초 휴식을 취하였다.

이후 $\mathrm{CyD}$ 기법을 적용하였다(Figure $1 \mathrm{C}$ ). $\mathrm{CyD}$ 는 원형, 나선형 표층 근막(superficial fascia)이 꼬이거나 얽힌 변형을 의미하며, 주위에 저리 거나 감각 이상, 경련 등 신경이나 혈관 장애의 증상을 유발한다. ${ }^{24}$ 이 경우 치료 방법은 손바닥의 넓은 면으로 얽힌 나선형 코일을 쓸어 내 림으로써 정상적인 형태의 근막으로 회복시키게 된다. ${ }^{24} \mathrm{~TB}$ 를 적용할 경우 뒤틀린 밴드형 근막을 풀어주게 되지만, 동시에 그 부위를 덮고 있는 코일형 표층근막의 얽힘, 즉 $\mathrm{CyD}$ 를 유발시키게 되므로, $\mathrm{TB}$ 치료 의 마지막에는 항상 $\mathrm{CyD}$ 를 적용해야 하는 것이 원칙이다. ${ }^{4}$ 이 기법을 위해 치료사는 오금부위부터 발바닥 끝까지 손바닥 넓은 면으로 쓸 어내리도록 하였으며, 이때 종아리 부위의 안쪽면, 중간면, 가쪽면을 각각 지나가도록 3 회 적용하였다. 치료 강도는 피험자의 반응을 피드 백 하면서 피험자가 참을 수 있을 정도로 적용하였다. 총 치료 시간은 5 분이 소요되었다.

\section{(2) 폼롤링(FR)}

$\mathrm{FR}$ 그룹은 길이 $60 \mathrm{~cm}$, 지름 $15 \mathrm{~cm}$ 인 EVA 재질의 폼롤러를 사용하였 으며, 폼롤러를 실험측 종아리세갈래근 아래에 두고 비실험측 다리 를 실험측 다리 위에 올리도록 하여 체중을 실을 수 있도록 하였다. 이후 폼롤러를 근섬유 방향으로 밀고 당기면서 그 부위에 압박을 가 하여 마사지할 수 있도록 하였으며, 장딴지의 안쪽, 중간, 가쪽 방향에 서 각 1 분씩 적용 후 20 초간 휴식을 취하였다. 마지막으로 근복 부근 에서 좌우 방향으로 1 분간 적용하였다. 선행연구에서 FR은 보통 30 초 에서 1분간 2-5회 적용하였으므로, ${ }^{13,15,17,25}$ 본 실험에서도 비슷한 시간 과 횟수로 적용하였다. 치료 강도는 가능한 한 체중을 최대한 싣도록
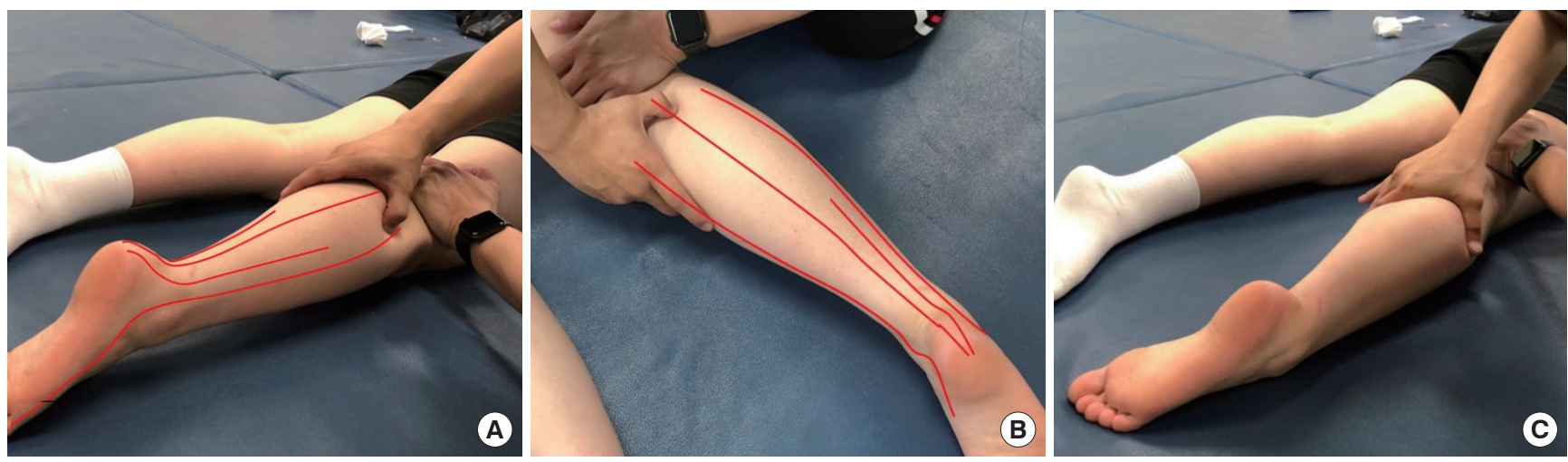

Figure 1. Application of Fascial distortion model (FDM) on a calf muscle. (A, B) From left to right, posterior medial, posterior, lateral Achilles tendon and posterior lateral trigger bands (TB)(red lines), (C) Cylinder distortion (CyD). 
하였다. 총 치료 시간은 FDM과의 비교를 위해 FDM에서 소요된 시간 과 동일하게 5 분이 소요될 수 있도록 하였다.

(3) 자가 신장(SS)

FDM과 FR와의 비교를 위해 대조군은 무릎을 펴고 앉은 자세에서 앞발의 발바닥 부근에 수건을 걸어 몸쪽으로 잡아 당기는 방법으로 종아리세갈래근을 스트레칭 하였다. 1 분간 적용 후 20 초 휴식을 취 하도록 하였으며, 총 4 세트를 적용하여 총 치료 시간이 5 분이 되도록 하였다.

\section{3. 실험 절차}

실험 전 피험자를 FDM, FR, SS 그룹으로 분류하였으며, 각 그룹에 맞 는 중재를 적용하였다. 중재 적용 전, 후에 DF ROM을 측정하였으며, $\mathrm{ROM}$ 은 열린 사슬과 닫힌 사슬에서 측정하였다. 그 후 세 그룹 간에

Table 2. Comparison of ankle dorsiflexion range of motion between pre-and post-intervention and among three groups

$($ mean \pm SD)

\begin{tabular}{|c|c|c|c|c|c|}
\hline Position & & FDM $\left(^{\circ}\right)$ & $\mathrm{FR}\left({ }^{\circ}\right)$ & SS $\left({ }^{\circ}\right)$ & $p$ \\
\hline \multirow[t]{4}{*}{ OKC } & Pre & $12.8 \pm 6.16$ & $11.0 \pm 7.18$ & $11.4 \pm 4.79$ & 0.790 \\
\hline & Post & $17.4 \pm 5.38$ & $11.7 \pm 6.17$ & $13.4 \pm 3.98$ & 0.090 \\
\hline & Change & $4.6 \pm 2.27^{\S, \|}$ & $0.7 \pm 0.67$ & $2.0 \pm 2.71$ & $0.001^{+}$ \\
\hline & $\mathrm{p}$ & $<0.001^{+}$ & $0.010^{\star}$ & $0.044^{*}$ & \\
\hline \multirow[t]{4}{*}{ CKC } & Pre $\neq$ & $18.8 \pm 7.81$ & $16.2 \pm 6.65$ & $17.6 \pm 4.01$ & 0.662 \\
\hline & Post & $24.0 \pm 6.46^{5}$ & $17.6 \pm 6.17$ & $18.9 \pm 4.48$ & $0.047^{*}$ \\
\hline & Change & $5.2 \pm 3.94^{\S, \|}$ & $1.4 \pm 1.43$ & $1.3 \pm 1.77$ & $0.003^{+}$ \\
\hline & $\mathrm{p}$ & $0.002^{+}$ & $0.013^{*}$ & $0.045^{*}$ & \\
\hline
\end{tabular}

${ }^{*} p<0.05,{ }^{+} p<0.01,{ }^{\ddagger}$ WBLT as an inclusion criteria $\left(\leq 30^{\circ}\right),{ }^{8}$ significantly different compared to FR, "significantly different compared to SS.

SD: Standard deviation, FDM: Fascial distortion model group, FR: Foam rolling group, SS: Self-stretching group, OKC: Open kinetic chain measured in supine position, CKC: Closed kinetic chain measured in standing.
중재 전과 후의 $\mathrm{DF} \mathrm{ROM}$ 을 각각 비교하였으며, 중재 전후의 ROM 변 화량 또한 비교하였다. ROM 변화량은 중재 후 ROM에서 중재 전 $\mathrm{ROM}$ 을 뺀 값으로 계산하였다.

\section{4. 자료분석}

피험자의 일반적인 특성을 알아보기 위해 기술 통계를 실시하였다. 세 그룹간의 일반적인 특성을 비교하기 위해 일요인 분산분석을 사 용하였으며, 중재 전 WBLT를 비롯하여 모든 일반적인 특성에서 세 그룹간 유의한 차이가 없었다. Shapiro-Wilk 검사를 실시한 결과 정규 성이 검정 되어 일요인 분산분석을 실시하여 세 그룹 간에 수집된 변 수의 차이를 알아보았다. 유의 수준이 확인되면 Tuckey HSD 검사를 실시하여 사후 검정을 하였다. 또한 그룹 내 치료 전후 변화를 알아보 기 위해 paired t-test를 실시하였다. 통계는 윈도우용 SPSS version 20을 이용하였으며, 유의 수준은 $\alpha=0.05$ 로 설정하였다.

\section{결 과}

\section{1. 그룹 내 DF ROM 전후 비교}

각 중재의 효과가 있는지를 알아보기 위해 중재 내 ROM의 전후를 비 교한 결과 세 그룹 모두 열린 사슬 자세와 닫힌 사슬 자세에서 유의 한차이가 있었다 $(\mathrm{p}<0.05)$ (Table 2, Figure 2).

\section{2. 세 그룹간 DF ROM 비교}

열린 사슬에서 측정한 DF ROM을 비교한 결과 중재 전과 후에는 세 그룹간에 유의한 차이가 없었으나 $(\mathrm{p}>0.05)$ 중재 전후의 ROM 변화량 의 경우 유의한 차이가 있었다 $(\mathrm{p}<0.01)$. 사후 검정 결과 $\mathrm{FDM}$ 그룹과 $\mathrm{FR}$ 그룹(p<0.01), FDM 그룹과 SS 그룹 사이에 유의한 차이가 있었다 $(\mathrm{p}<0.05)($ Table 2, Figure 2A).

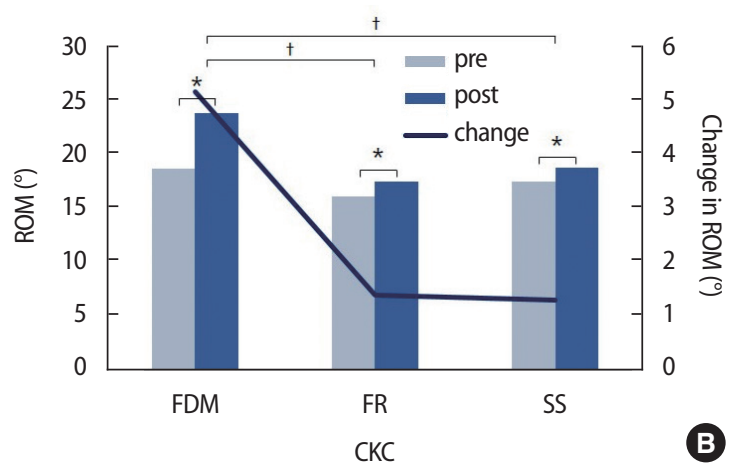

Figure 2. Comparison of ankle dorsiflexion range of motion between pre- and post-intervention and among groups. ${ }^{*}$ Range of motion is significantly different between pre- and post-intervention, ${ }^{+}$Change in range of motion is significantly different among groups, OKC: Open kinetic chain, CKC: Closed kinetic chain, FDM: Fascial distortion model, FB: Foam rolling, SS: Self-stretching, pre: ankle dorsiflexion range of motion before intervention, post: ankle. dorsiflexion range of motion before intervention, Change: Change in ankle dorsiflexion range of motion between pre-and post-intervention 
닫힌 사슬에서 측정한 $\mathrm{DF} \mathrm{ROM}$ 의 경우 중재 전에는 세 그룹 간에 유의한 차이가 없었으나 $(\mathrm{p}<0.05)$, 중재 후에는 유의한 차이가 있었으 며 $(\mathrm{p}<0.05)$, 사후 검정 결과 $\mathrm{FDM}$ 그룹과 $\mathrm{FR}$ 그룹 사이에 유의한 차이 가 있었다 $(\mathrm{p}<0.05)$. 중재 전후의 ROM 변화량에도 세 그룹 간에 유의 한 차이가 있었으며 $(\mathrm{p}<0.01)$, 사후 검정 결과 $\mathrm{FDM}$ 그룹과 $\mathrm{FR}$ 그룹 $(\mathrm{p}<0.01), \mathrm{FDM}$ 그룹과 SS 그룹 $(\mathrm{p}<0.01)$ 사이에 유의한 차이가 있었다 (Table 2, Figure 2B).

\section{고 찰}

$\mathrm{FDM}$ 은 근막 치료 접근법 중 하나로, 빠른 시간 내에 통증을 감소시 키고 기능을 회복시키는 효과적이고 효율적인 치료 방법이나 그 효 과를 과학적으로 검증한 연구는 많지 않다. 폼롤러를 이용한 자가 근 막 이완 기법은 단시간에 효과를 볼 수 있는 또 다른 근막 치료 접근 법으로, 쉽고 간편하게 적용할 수 있다는 점 때문에 임상에서 많이 사용되고 있다. 본 연구에서는 임상에서 흔히 활용되는 폼롤러를 이 용하여 종아리세갈래근에 자가 근막 이완을 실시하였으며(폼롤링 그룹, FR), 일반적인 발목관절 스트레칭 방법인 수건으로 발목 잡아 당기기를 대조군(자가 신장 그룹, SS)으로 정하여 이를 $\mathrm{FDM}$ 의 효과 와 비교하였다. 이를 위해 선 자세에서 수행하는 WBLT를 통해 닫힌 사슬에서의 DF ROM을, 바로 누운 자세에서 측정하여 열린 사슬에 서의 DF ROM을 측정하였으며, 중재 전후의 DF ROM과 ROM 변화 량을 측정하여 그룹 간 차이 비교, 그룹 내 전후 비교를 하였다. 그 결 과 세 중재법 모두 DF ROM을 증가시키는 데 효과적인 것으로 나타 났으나, WBLT 결과 그룹 간에는 FDM이 FR 보다 더 효과적인 것으로 나타났다. 특히, 중재 전후의 ROM 변화량에서는 열린 사슬과 닫힌 사슬 모두에서 FDM이 FR과 SS 보다 더 효과적인 것으로 나타났다.

$\mathrm{FDM}$ 이나 폼롤링 외에도 $\mathrm{ROM}$ 을 증가시키는 다양한 방법들이 있 지만, ${ }^{26-28} \mathrm{FDM}$ 의 가장 큰 특징은 짧은 시간 내에 최대의 효과를 볼수 있다는 것이다.469 따라서 본 연구에서는 짧은 시간 동안의 즉각적인 $\mathrm{ROM}$ 개선 효과를 비교하기 위해 세 그룹 모두 5 분 동안의 치료 시간 을 적용하였으며, 그 결과 $\mathrm{FDM}$ 이 다른 그룹보다 더 효과적이었다. 주 로 8-20분 동안 폼롤링을 수행한 선행연구에 비추어 볼 때15,25,29 5 분 의 적용시간은 폼롤링의 효과가 나타나는 데에 불충분한 시간이라 할 수 있으며, 이는 FDM이 폼롤링보다 더 빠른 효과가 있었다고 할 수 있다. Fink 등 6 은 유착성 관절주머니염 환자에게 FDM과수동 도수 치료를 적용하여 능동 벌림 $\mathrm{ROM}$ 을 측정해 본 결과 $\mathrm{FDM}$ 이 수동 도 수치료에 비해 더 빠르고 두드러진 효과를 보였다고 하였다. Richter 등9은 급성 허리통증에 대한 독일 국가 질병 관리 지침(German national disease management guideline)에 따른 치료법과 FDM을 비교하 였으며, 그 결과 $\mathrm{FDM}$ 의 효과가 더 빨리 나타났고 통증 감소와 기능
향상에 더 효과적이라고 하였다. 이러한 선행연구는 $\mathrm{FDM}$ 의 빠른 효 과를 증명한 본 연구의 결과와 일치한다.69

이렇게 빠른 적용 시간과 적절한 치료 효과는 스포츠 경기와 같이 짧은 시간 내에 선수들의 통증을 감소시키고 기능을 회복시켜야 하 는 순간에 적절하다. 임상에서는 통증이나 기능부전 환자들의 통증 기간을 감소시키고, 기능을 빠른 시간 내에 회복시킴으로써 삶의 질 을 향상시킬 수 있으며, 치료 비용 또한 감소시킬 수 있다. 뿐만 아니 라, 즉각적인 치료 효과를 통해 환자가 치료 중간에 포기하지 않고 치 료를 끝마칠 수 있도록 동기 부여도 할 수 있다?

$\mathrm{FDM}$ 의 기전은 $\mathrm{FDM}$ 의 이론 및 가설, 근막의 성질, 그리고 골지힘 줄기관의 역할로 설명이 가능하다. $\mathrm{FDM}$ 은 피부 아래 근막을 따라 존 재하는 교차결합(crosslink)을 제거하여 정상적인 수준으로 회복시키 는 치료법이다. 인체에 가해지는 비정상적인 외력으로 인한 급성 손 상이나 만성적인 장력이 발생할 경우 근막에 뒤틀림, 꼬임, 분리 등 여 러 형태의 변형이 발생하게 되고, 이러한 변형이 통증이나 기능부전 등의 증상을 유발할 수 있다는 것이 FDM의 이론이다. ${ }^{424}$ 이를 해결하 기 위해 변형을 정상상태로 돌려 놓을 수 있는 강한 외력을 물리적으 로 가하는 것이 $\mathrm{FDM}$ 의 치료적 방법이며, 변형의 유형에 따라 6 가지 유형 중 하나 이상의 치료법을 적용할 수 있다. 이는 근막에 압력이나 열이 가해지면 더 부드러워지고 액체화되는 결합조직의 성질, 즉, 점 탄성(viscoelasticity)이나 요변성(thixotrophy)을 이용한 방법으로, 교 차결합에 가하는 강한 압박력을 통해 유착되거나 변형된 근막을 이 완시킬 수 있다.,24 또한 장력이 주어질 경우 골지힘줄기관이 활성화 되어 반사적인 운동 뉴런을 억제 시킴으로써 근육이 이완될 수 있다 는 기전으로도 설명이 가능하다. 이렇게 획득된 근막의 이완을 통해 $\mathrm{ROM}$ 이 증가되며, 혈액이나 림프의 원활한 흐름으로 통증을 감소시 킬 수 있을 것이라 생각된다.

폼롤링 또한 단시간 적용으로도 일반적인 효과를 낼 수 있다. ${ }^{14}$ 선 행 연구에서 적용된 폼롤링의 치료 시간은 주로 8 분에서 20 분 사이 로 ${ }^{15,25,29}$ 이는 본 연구에서 적용한 시간보다 더 긴 시간이다. 5 분간 적 용한 폼롤링의 효과는 같은 시간 적용한 FDM보다 ROM 증가량이 적었으므로, $\mathrm{FDM}$ 이 폼롤링보다 단시간에 더 큰 효과가 있음을 알 수 있다. 통계학적으로 유의한 차이는 없었으나, 수건을 이용한 자가 신장에 비해 폼롤링 적용이 열린 사슬에서는 더 작은 증가량을, 닫힌 사슬에서는 더 큰 증가량을 보였다. 이는 체중을 실어 근육을 이완시 키는 폼롤링의 경우 체중 부하가 된 상태의 WBLT에서 더 큰 효과를 보인 반면, 손으로 수건을 잡아당겨 근육을 스트레칭 했던 자가 신장 의 경우 열린 사슬에서 더 큰 효과를 보인 것으로 사료된다. 일상 생 활에서는 주로 보행과 같은 닫힌 사슬에서의 DF ROM이 더욱 필요하 므로, 체중을 부하시킨 상태에서 적용하는 폼롤링이 더욱 필요할 것 으로 보이며, 목적에 따라 스트레칭 방법을 선택할 필요가 있다. 하지 
만 폼롤링과 자가 신장 또한 치료 전후에 유의한 차이를 보였으므로, 두 방법 모두 단시간의 적용으로 DF ROM을 증가시킬 수 있는 유의 한 방법이라할수 있다.

본 연구의 제한점은 5 분간의 치료 효과가 얼마나 오랫동안 지속되 는지를 알아볼 수 있도록 중재 후 사후검증을 실시하지 않았다는 점 이다. FDM이 빠른 효과를 가지지만 이 효과의 지속성에 대한 연구가 진행된다면 단시간의 치료임에도 오래 지속되는 시간 대비 효과의 지 속성, 즉, 치료의 효율성을 증명할 수 있을 것이라 생각된다. 또한 피험 자 수가 적어 일반화 하기에 어려운 점이 있으며, 향후 많은 수의 피험 자를 대상으로 무작위 배당 실험, 맹검법 등을 적용한 연구가 필요하 다. 또한 치료적 스트레칭 적용 시 남녀 간의 반응이 다르므로, ${ }^{23}$ 남녀 간의 차이를 비교한 연구가 필요할 것이다.

본 연구는 FDM, FR, SS의 적용이 DF ROM에 미치는 영향을 비교 함으로써 단시간 적용 시 치료 효과가 가장 좋은 치료법이 무엇인지 를 알아보고자 하였다. 세 방법 모두 중재 후에 ROM 개선의 효과를 보였으나, FDM이 다른 방법들에 비해 더 큰 효과를 보였다. 따라서 빠른 시간 내에 ROM 개선의 효과를 보고자 하는 임상가들에게 적 절한 중재로 FDM을 제시할 수 있을 것이라 생각된다.

\section{REFERENCES}

1. Findley TW, Schleip R. Fascia research: Basic science and implications for conventional and complementary health care. Munich, Elsevier Urban and Fischer, 2007;2-7.

2. Rajasekar S, Marchand AM. Fascial manipulation for persistent knee pain following ACL and meniscus repair. J Bodyw Mov Ther. 2017;21 (2):452-8.

3. Stanek J, Sullivan T, Davis S. Comparison of compressive myofascial release and the graston technique for improving ankle-dorsiflexion range of motion. J Athl Train. 2018;53(2):160-7.

4. Typaldos S. FDM: Clinical and theoretical application of the Fascial Distortion Model within the practice of medicine and surgery. 4th ed. Bangor, Typaldos Publishing Co, 2002;3-60.

5. Kim MK, Lee WJ. Effect of Fascial Distortion Model on the pain and movement of neck patient. J Kor Phys Ther. 2019;31(1):24-30.

6. Fink M, Schiller J, Buhck H. Efficacy of a manual treatment method according to the fascial distortion model in the management of contracted (“Frozen") shoulder. Z Orthop Unfall. 2012;150(4):420-7.

7. Schulze C, Finze S, Bader R et al. Treatment of medial tibial stress syndrome according to the fascial distortion model: A prospective case control study. Sci World J. 2014;2014:790626.

8. James SJ, Hudnall J. Use of the fascial distortion model to evaluate a limp in a child. J Am Osteopath Assoc. 2017;117(6):399-402.

9. Richter D, Karst M, Buhck $\mathrm{H}$ et al. Efficacy of fascial distortion model treatment for acute, nonspecific low-back pain in primary care: A prospective controlled trial. Altern Ther Health Med. 2017;23(5).

10. Lee WJ. Effect of fascial distortion model on the cobb's angle in adoles- cents with idiopathic scoliosis. J Kor Phys Ther. 2019;31(1):31-4.

11. Thalhamer C. A fundamental critique of the fascial distortion model and its application in clinical practice. J Bodyw Mov Ther. 2018;22 (1):112-7.

12. Cheatham SW, Kolber MJ, Cain M et al. The effects of self-myofascial release using a roam roll or roller massager on joint range of motion, muscle recovery, and performance: A systematic review. Int J Sports Phys Ther. 2015;10(6):827-38.

13. Yun SJ, Kim MH. Effects of shoulder abduction in opposite directions on EMG activity in the abdominal muscles during single leg raising in the supine position on the foam roller in healthy subjects. J Kor Phys Ther. 2015;27(4):270-4.

14. De Souza A, Sanchotene CG, Lopes C et al. Acute effect of 2 self-myofascial release protocols on hip and ankle range of motion. J Sport Rehabil. 2018;28(2):159-64.

15. Macdonald GZ, Button DC, Drinkwater EJ et al. Foam rolling as a recovery tool after an intense bout of physical activity. Med Sci Sports Exerc. 2014;46(1):131-42.

16. Halperin I, Aboodarda SJ, Button DC et al. Roller massager improves range of motion of plantar flexor muscles without subsequent decreases in force parameters. Int J Soprts Phys Ther. 2014;9(1):92-102.

17. Pearcey GE, Bradbury-Squires DJ, Kawamoto JE et al. Foam rolling for delayed-onset muscle soreness and recovery of dynamic performance measures. J Athl Train. 2015;50(1):5-13.

18. Weir J, Chockalingam N. Ankle joint dorsiflexion: Assessment of true values necessary for normal gait. Int J Ther Rehabil. 2007;14(2):76-82.

19. Willems TM, Witvrouw E, Delbaere K et al. Intrinsic risk factors for inversion ankle sprains in male subjects: A prospective study. Am J Sports Med. 2005;33(3):415-23.

20. Young R, Nix S, Wholohan A et al. Interventions for increasing ankle joint dorsiflexion: A systematic review and meta-analysis. J Foot Ankle Res. 2013;6(1):46.

21. Chisholm MD, Birmingham TB, Brown J et al. Reliability and validity of a weight-bearing measure of ankle dorsiflexion range of motion. Physiother Can. 2012;64(4):347-55.

22. Park JW, Park S. Inter-rater reliability of cervical proprioception, dynamic balance and dorsiflexion range of motion using STARmat'. J Kor Phys Ther. 2020;32(2):88-93.

23. Gajdosik RL. Relation of age and passive properties of an ankle dorsiflexion stretch to the timed one-leg stance test in older women. Percept Mot Skills. 2006;103(1):177-82.

24. Römer F. Practical Manual of the Fascial Distortion Model. FDM Shop. 2015:18-179.

25. Bushell JE, Dawson SM, Webster MM. Clinical relevance of foam rolling on hip extension angle in a functional lunge position. J Strength Cond Res. 2015;29(9):2397-403.

26.Lee JH, Kim JY, Kim HS et al. Comparison of sit and reach test, straight leg raise test and visual analogue scale when applying static stretching and mulligan's two leg rotation in young adults with hamstring shortness. J Kor Phys Ther. 2019;31(5):266-72.

27. Kim KS, Jeon IC. Effectiveness of iliopsoas self-stretching on hip extension angle, gluteus maximus activity, and pelvic compensations during prone hip extension in subjects with iliopsoas shortness. J Kor Phys Ther. 2018;30(1):23-8. 
28. Kang TW, Kim BR. The effects of stretching and strengthening exercise on the pain, pelvic tilt, functional disability index, and balance ability of patients with chronic lower back pain. J Kor Phys Ther. 2019;31(1):7-12.
29. Jeon HM. The effects of interventions that increase the ankle dorsi-flexion on muscle contraction and dynamic balance. Catholic University of Daegu. Dissertation of Master's Degree. 2019. 